\title{
Laboreal
}

Volume $5 \mathrm{~N}^{\circ} 2$ | 2009

Varia

\section{Análise e estrutura do trabalho de Jean-Marie} Faverge

Análisis y estructura del trabajo de Jean-Marie Faverge

Analyse et structure du travail de Jean-Marie Faverge

Analysis and structure of the work of Jean-Marie Faverge

\section{Régis Ouvrier-Bonnaz}

Tradutor: Andreia Ferreira

\section{OpenEdition}

\section{Journals}

\section{Edição electrónica}

URL: http://journals.openedition.org/laboreal/9929

DOI: 10.4000/laboreal.9929

ISSN: 1646-5237

\section{Editora}

Universidade do Porto

\section{Refêrencia eletrónica}

Régis Ouvrier-Bonnaz, « Análise e estrutura do trabalho de Jean-Marie Faverge », Laboreal [Online], Volume $5 \mathrm{~N}^{\circ} 2$ | 2009, posto online no dia 01 dezembro 2009, consultado o 24 setembro 2020. URL : http://journals.openedition.org/laboreal/9929 ; DOI : https://doi.org/10.4000/laboreal.9929

Este documento foi criado de forma automática no dia 24 setembro 2020.

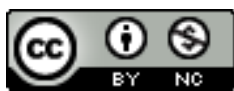

Laboreal está licenciado com uma Licença Creative Commons - Atribuição-NãoComercial 4.0 Internacional. 


\title{
Análise e estrutura do trabalho de Jean-Marie Faverge
}

\author{
Análisis y estructura del trabajo de Jean-Marie Faverge \\ Analyse et structure du travail de Jean-Marie Faverge \\ Analysis and structure of the work of Jean-Marie Faverge
}

\section{Régis Ouvrier-Bonnaz}

Tradução : Andreia Ferreira

\section{REFERÊNCIA}

Artigo original : Faverge, J.-M. (1952). Analyse et structure du travail. Bulletin du Centre d'Études et de Recherches Psychotechniques (CERP), n¹, janvier-juin.

1 Este primeiro texto de Jean-Marie Faverge (1912-1988) [1] apresentado na rubrica "Textos Históricos" da revista pode surpreender o leitor actual pela aridez da sua concisão crítica. O seu primeiro mérito é o de ir ao essencial na sua forma de por em causa um método analítico que, fragmentando o estudo do comportamento humano no trabalho, não permite tê-lo em conta. Nesta curta apresentação, partiremos do contexto da época para melhor compreender e estudar os problemas colocados e fazer uma comparação com aqueles que reencontramos hoje em dia. Como disse Clot (2008, p.2), director do Centre de Recherche sur le Travail et le Développement (CRTD) do Conservatoire National des Arts et Métiers do qual faz parte o Groupe de Recherche sur l'histoire du Travail et de l'Orientation (GRESHTO) que coordenamos, o que nos interessa aqui, é "de procurar junto dos anciãos como (nos) medir face aos problemas actuais".

2 Para Faverge, o método psicotécnico, quando tenta isolar os elementos da sua estrutura de conjunto para explicitar o comportamento do trabalhador em situação, não permite "dar conta do comportamento real e não pode mais do que fazer nascer o verbalismo". o propósito é categórico e por ser perfeitamente compreensível necessita de ser posto 
em perspectiva histórica tendo em conta a obra de Faverge e a sua inscrição institucional. $O$ interessa dessa obra para a análise do trabalho está actualmente bem estabelecido como o testemunham os textos publicados em sua homenagem no número especial da revista "Travail Humain" em 1982. Num texto com um título sugestivo "La politique du regard" [a política do olhar], de Keyser $(1982$, p. 95) precisa o carácter inovador deste contributo: "As obras clássicas de psicologia industrial que precederam Faverge ou que não foram influenciadas por ele, surpreendem o leitor por uma dupla característica : a ausência de relevo e a influência que eles tentam exercer sobre os trabalhadores ... falta-lhes o "retorno" que permite, através do comportamento de descobrir a actividade psicológica ... ele, preocupa-se pouco de submeter, de maneira mais ou menos hábil, o indivíduo aos imperativos da produção. É a dinâmica das relações que esta última entretém com o seu meio de trabalho que lhe interessa, e as suas eventuais perturbações". E acrescenta rendendo homenagem ao respeito que Faverge tinha pelo trabalho dos profissionais: "nós não descobrimos nada dizia Faverge. Nós nunca descobrimos nada. Nós contentamo-nos a fazer aparecer aquilo que estava na sombra". Faverge relativiza a posição de expert: os profissionais são os melhor colocados para falar do seu trabalho. Eles podem dizer e explicar se lhes dermos os meios.

3 Este texto não pode ser totalmente compreendido se nos abstrairmos do seu meio de publicação e do organismo que assegura o seu suporte de difusão. Ele aparece policopiado no primeiro número do Bulletin du Centre d'Etudes et de Recherches Psychotechniques (CERP) criado em 1946. Ombredane (1898-1958) foi nomeado director deste centro e recruta em 1947 um professor agregado de matemática, Jean-Marie Faverge, a quem ele confia a direcção de um serviço de tratamento estatístico. Nesse ano de 1946, tem que se formar com urgência uma mão-de-obra qualificada susceptível de ajudar na reconstrução de um país duramente afectado por cinco anos de guerra. $O$ CERP é colocado sob a co-tutela do Ministère du Travail e de um organismo, a Association pour la formation rationnelle de la main-d'oeuvre (AFRMO) du centre scientifique de la main d'oeuvre (CSMO) criado em 1938 sob a responsabilidade científica de J.-M. Lahy (1872-1945). A missão da AFRMO é de assumir a iniciativa de todos os estudos relativos às condições fisiológicas e psicotécnicas do trabalho, de elaborar os métodos de selecção e de formação profissional, de proceder à formação dos seleccionadores e dos monitores dos centros de formação profissional. Duas concepções da psicotécnica, da formação de psicotécnicos e dos métodos a utilizar para a selecção profissional se opõem, a da Direction de l'Enseignement Technique do Ministère de l'Education Nationale e a preconizada pela Direction de la main d'oeuvre du Ministère du Travail apoiada pelo Institut National de Formation des Cadres (INFCP) que privilegia um método de selecção, chamado método Carrard (1953, nome de um engenheiro suíço fundador em 1927 da "Fondation suisse pour la psychotechnique ». As razões dessa escolha, provavelmente ligadas, em parte, a um encontro tardio entre o Ministério do Trabalho e da Psicotécnica, parecem bastante obscuras. 0 método Carrard construído tendo por base uma decomposição analítica dos gestos profissionais susceptíveis de permitir a articulação entre os métodos de selecção e aprendizagem, afasta-se das preocupações da escola francesa de psicotécnica [2]. Faverge denuncia os procedimentos de selecção baseados exclusivamente na observação do "comportamento aparente" associando-se assim à posição expressa desde 1931 por Lahy: "quando determinamos as atitudes mentais e motrizes do sujeito enquanto ele executa o seu trabalho, temos que o exprimir em linguagem psicológica. Ora não há correspondência rigorosa entre cada uma dessas atitudes e as "funções" que, seguindo os dados da psicologia 
clássica, fragmentam o indivíduo. Quando acreditamos descobrir, por exemplo, que a atenção intervém num trabalho, nós sentimos no entanto que os testes ordinários de atenção concentrada $e$ atenção difusa não chegarão a alcançar a função - muito complexa - posta efectivamente em jogo" (Lahy \& Korngold, 1931, p.133). A crítica de Faverge emitida após um estudo rigoroso do método Carrard realizado desde 1947 a pedido de Ombredane é incontestável. Construída a partir de uma avaliação estatística rigorosa, ela inscreve-se na crítica levada a cabo no quadro mais geral da teoria das aptidões. Como precisa Jacques Leplat que sucede a Faverge na direcção do serviço de investigação do CERP em 1958: "a releitura das discussões que apaixonaram os psicólogos dessa época pode ajudar a melhor compreender os conceitos mais na moda hoje em dia, mas cuja natureza não é sempre claramente definida" (1991, p. 265). A análise de Faverge conserva toda a sua pertinência num momento em que a noção de aptidão reaparece sem grande discernimento, escondendo-se por vezes sob a vestimenta moderna de competência [3].

O seu questionamento é completo no artigo apresentado, apoia-se numa primeira parte sobre uma crítica aos métodos utilizados no quadro da racionalização do trabalho pela análise dos tempos no trabalho resultantes do taylorismo e fordismo da primeira metade do século XX e mais particularmente sobre o "méthod time measurement" (MTM). Este método decompõe cada gesto realizado por um executante e codifica-o atribuindo-lhe uma letra, por exemplo a letra $\mathrm{R}$ para a acção que consiste em "alcançar" (são assim utilizados 19 códigos). Para Faverge, "Um elemento, tal como esperar, virar, tem um significado e corre-se o risco de fazer uma má separação se isolarmos o gesto do seu objecto ». A acção não nasce do nada. Este ponto de vista implica uma distinção conceptual : o objecto da operação e o objecto da acção não se sobrepõem. Não há acção sem intenção, sem representação consciente do resultado a alcançar. Ele parte deste ponto de vista para desenvolver a sua crítica da noção de aptidão. Ele censura o método Carrard, a sua definição imprecisa de aptidão e a decomposição arbitrária da actividade que ele conduz. Ele apoia a sua crítica no exemplo do perfil-tipo da costureira de camisas de homem (perfil dado no artigo) : "Não vamos parar para mostrar o nosso sorriso pela preocupação de precisão nos níveis da aptidão, não insistiremos em conhecer a população de referência

na qual as percentagens são válidas, nem questionaremos se as variáveis são quantitativas e apreciáveis em graus, etc... examinaremos simplesmente as duas rubricas "golpe de vista [coup d'oeil]" e "precisão gestual [sûreté gestuelle]" que o autor considera como particularmente importantes para este posto de trabalho".

5 Faverge interroga : "O que se entende por golpe de vista”. Esta interrogação é retomada praticamente palavra a palavra no capítulo $\mathrm{V}$ do livro escrito com Ombredane publicado em 1955 "Análise do Trabalho". Ele interroga-se a partir da aprendizagem da operação de ladrilhagem que ele próprio conduziu como indicado no artigo precisando assim, sem exagerar, a importância da aprendizagem da profissão ou de certos gestos da profissão em situação para o psicólogo do trabalho. Faverge é lúcido, ele desconfia do dogma da experiência imediata, "as nossas primeiras observações, quando aprendemos uma profissão para a compreender, são frequentemente pouco importantes, qualquer que seja o interesse que colocámos na sua observação, porque a natureza do trabalho muda a seguir e elas correspondem a nada mais que um momento da aprendizagem rapidamente apagado ». Assim como a tarefa que consiste em montar um muro de tijolos : " um belo dia ... constatamos que posicionamos bem e rapidamente os tijolos e que pusemos de parte todas as recomendações, limitando-nos a colocar o nosso tijolo sem hesitações orientando-o por uma vista de olhos ao canto da direita, 
formado pela aresta vertical do nosso tijolo e a aresta horizontal do tijolo da fila de baixo. Faverge deduz que o êxito da actividade aqui em questão não está ligada à possessão de uma aptidão específica mas a uma competência adquirida progressivamente que consiste em colocar o olho no bom lugar. Para ele, "estamos longe das capacidades ligadas aos mecanismos do espírito: julgamento, raciocínio, atenção » tais como foram definidas pelo método Carrard. Na mesma lógica, ele dá no fim do artigo o exemplo de uma tarefa de soldadura para mostrar os perigos de uma análise sumária que conduziria a uma identificação errada da dificuldade crítica da actividade. Para ele como indica na conclusão a partir deste exemplo, " aptidão... não representa nada sem o significado da tarefa proposta». Como bom matemático, Faverge atribui à análise factorial o mérito de permitir reagrupar as tarefas em função do seu significado. Para Clot e Leplat (2005, p. 296), Faverge parece ter sido um dos primeiros a ver "o interesse do método clínico na análise do modo de aquisição da experiência e na análise das competências tácitas ou incorporadas ». Ao ter em conta este significado ligado à resolução da tarefa, Faverge fará uma constatação : nenhuma actividade é parecida com uma outra. Esta diversidade induz a escolha de um ângulo de observação e de abordagem metodológica.

6 Este texto "Estrutura e análise do trabalho" publicado em 1952 anuncia o início do movimento de ergonomia de língua francesa. 0 seu grande mérito é o de introduzir um problema de fundo que não pára de interrogar a psicologia em geral e a psicologia do trabalho em particular relativo à ligação entre o singular ligado à variabilidade de condutas observadas em situação e à generalização necessária à investigação científica. Também a esse título, a análise de Faverge permanece actual.

\section{BIBLIOGRAFIA}

Carrard, A. (1953). Psychologie de l'homme au travail. Berne et Paris : Delachaux et Niestlé.

Clot, Y. (2008). Travail et pouvoir d'agir. Paris: PUF.

Clot, Y. \& Leplat, J. (2005). La méthode clinique en ergonomie et en psychologie du travail. Le Travail Humain, vol. 68, 4, 289-316.

De Keyser, V. (1982). La politique du regard. In Hommage à Jean-Marie Faverge. Le Travail Humain, vol. 45, 1, 94-100.

Lahy, J.-M. \& Korngold, S. (1931). Sélection des opératrices de machines comptables. L'Année psychologique, 32, 131-149.

Leplat, J. (1991). Compétence et ergonomie. In R. Amalberti, M. de Montmolin \& J. Theureau (dir.). Modèles en analyse du travail [pp. 263-278]. Liège : Mardaga.

Ombredanne, A. \& Faverge, J.-M. (1955). L'analyse du travail. Paris : PUF. 


\section{NOTAS}

1. Pode reportar-se à biografia deste autor editada no Bulletin da SELF, no 149 , Março 2008, 12-19.

2. Sobre a história da escola francesa de psicotécnica e o contributo de J.-M. Lahy, pode reportarse ao artigo editado na revista: Ouvrier-Bonnaz, R. (2007). A psicologia em França de 1870 a 1840, de uma ciência aplicada a uma disciplina universitária. Laboreal, 3, (1), 57-63. http:// laboreal.up.pt/revista/artigo.php?id=37t45nSU5471122987295752361

3. $O$ texto de propostas de recomendação do parlamento europeu sobre as competências-chave para a educação e a formação ao longo da vida (Comissão das Comunidades Europeia, Bruxelas, 2005/0221) define desta forma sem análise crítica a competência como "um conjunto de conhecimentos, aptidões e atitudes" retomando quase de forma idêntica a definição de Carrard (1953, p. 32) de "homem inteligente".

\section{AUTORES}

\section{RÉGIS OUVRIER-BONNAZ}

Groupe de recherche sur l'histoire du travail et de l'orientation Centre de Recherche sur le Travail et le Développement Conservatoire National des Arts et Métiers, 41, Rue Gay Lussac 75005 Paris, France

regis.ouvrier_bonnaz@cnam.fr 